\title{
Erratum to: Identifying the spatial and temporal distribution characteristics of precipitation in Iran
}

\author{
G. A. Fallah Ghalhari ${ }^{1}$ A. A. Dadashi Roudbari ${ }^{2}$ - M. Asadi $^{3}$
}

Published online: 5 September 2016

(C) Saudi Society for Geosciences 2016

Erratum to: Arab J Geosci

DOI 10.1007/s12517-016-2606-4

The original version of this article, unfortunately, contained errors.

Author's family and given name were interchanged. Given in this article are the correct author names.

The online version of the original article can be found at http://dx.doi. org/10.1007/s12517-016-2606-4.

G. A. Fallah Ghalhari

ab_fa789@yahoo.com

1 Faculty of Geography and Environmental Sciences, Hakim

Sabzevari University, Sabzevar, Islamic Republic of Iran

2 Urban Climatology, Shahid Beheshti University, Tehran, Islamic

Republic of Iran

3 Agricultural Climatology, Hakim Sabzevari University,

Sabzevar, Islamic Republic of Iran 